\title{
Novas configurações do controle da loucura no Brasil: da crise do grande internamento ao modelo de atendimento descentralizado
}

\author{
Luís Antônio Francisco de Souza ${ }^{1}$ \\ Larissa Cristina Clemente Veiga ${ }^{2}$
}

\begin{abstract}
Resumo: O presente artigo pretende problematizar as novas configurações das políticas de saúde mental no Brasil contemporâneo. O saber médico psiquiátrico se constituiu através da criação e disseminação dos hospitais psiquiátricos como espaços privilegiados de controle e exclusão de doentes mentais. No Brasil, após a reforma psiquiátrica dos anos 1980, novas estratégias centradas no modelo ambulatorial e assistencial de atendimento foram estabelecidas como políticas públicas de saúde mental. No entanto, é possível observar a permanência e mesmo a retomada das práticas asilares. Na configuração atual, o internamento e o tratamento ambulatorial convivem com uma ampla prática de medicalização das "pessoas portadoras de transtornos mentais". Dois mecanismos têm acionado estas estratégias: o surto psiquiátrico e os usuários de crack.
\end{abstract}

Palavras-chaves: Psiquiatria, Internação psiquiátrica, Políticas públicas de saúde mental, Estado de exceção

\section{New configuration of madness control in Brazil: from the great internment crisis to the descentralized model of care}

\begin{abstract}
This article intends to discuss the new trends on mental health in contemporary Brazil. The psychiatry has formed by the creation and spread of mental health hospitals as a central space of control and exclusion of the insane. In Brazil, after 1980's the psychiatric reform, new strategies based on day and assistance care were stablished as mental health public policies. Nevertheless, it is possible to see the continuity and the reprisal of internment practices. In the new arrangement, the day care internment and treatment is set besides with the medical drugs use for the mental insanes. Two strategies are put forward: psychiatric "surto" and the crack addicts.
\end{abstract}

Key-words: Psychiatry. Psychiatric internment. Mental health public Policies. State of exception.

\footnotetext{
${ }^{1}$ Professor de sociologia no Departamento de Sociologia e Antropologia e no Programa de Pós-Graduação em Ciências Sociais da Unesp, campus de Marília. E-mail: 1afraso@ hotmail.com

2 Mestranda no Programa de Pós-Graduação em Ciências Sociais da Unesp, campus de Marília.
} 


\title{
1. Introdução
}

\begin{abstract}
"No meio do mundo sereno da doença mental, o homem moderno não se comunica mais com o louco: existe, por um lado, o homem de razão que delega o médico para a loucura, só autorizando assim uma relação através da universalidade abstrata da doença; existe, por outro lado, o homem de loucura que só se comunica com o outro por intermédio de uma razão igualmente abstrata, que é ordem, coerção física e moral, pressão anônima do grupo, exigência de conformidade. Linguagem comum não há; ou melhor, não há mais; a constituição da loucura como doença mental, no final do século XVIII, constata um diálogo rompido, dá a separação como já adquirida e faz cair no esquecimento todas essas palavras imperfeitas, sem sintaxe fixa, mais ou menos balbuciantes, através de que se dava o contato entre a loucura e a razão. A linguagem da psiquiatria, que é monólogo da razão sobre a loucura, só pode se estabelecer sobre tal silêncio. Não quis fazer a história desta linguagem; mas, antes, a arqueologia deste silêncio.” (FOUCAULT, 2006a)
\end{abstract}

A perspectiva deste artigo se inspira na história do presente de Michel Foucault, segundo a qual, a análise histórica está subordinada aos problemas do presente que podem ser problematizados a partir da experiência histórica não como continuidade dos processos de mudança, mas como acontecimentos que iluminam nossos pontos cegos, que dificultam a compreensão dos perigos da atualidade. A história da psiquiatria e dos hospitais psiquiátricos interessa nesse sentido porque indicam caminhos problemáticos que parecem reemergir como alternativas para as políticas de saúde mental no Brasil contemporâneo, sobretudo, a retomada do asilo e a disseminação de um poder na forma de uma medicalização geral da sociedade, começando com a presença massiva da indústria farmacêutica em nossas vidas por meio de autodiagnóstico e de automedicação. Mais do que isto, as estratégias do poder psiquiátrico modulam os mecanismos clássicos de captura da loucura como doença mental, voltados para a disciplina corporal e a promessa de cura e de controle do louco, com mecanismos contemporâneos que não dão mais e tão somente ênfase à doença, mas às síndromes e aos episódios que supostamente 
Revista NEP, Núcleo de Estudos Paranaenses, Curitiba, v.4, n.2, dez. 2018

expressam a loucura. Assim, a loucura vê-se confrontada com a doença mental e esta com o transtorno mental ${ }^{3}$.

A prática psiquiátrica, desde sua institucionalização na forma dos grandes hospitais psiquiátricos do começo do século XIX no Brasil, tem a internação como estratégia de interceptação e controle daqueles diagnosticados como loucos. Mesmo que no período atual esta estratégia tenha ganhado contornos restritivos, aliada a outras técnicas como a medicalização e o sistema ambulatorial, ela compõe um dispositivo híbrido de captura da loucura em nossa sociedade. Para efeito do presente texto, os termos loucura, doença mental e transtorno mental estão correlacionados, mas sabemos, a partir das análises de Michel Foucault, que não devemos confundir estes termos, na medida em que remetem a regimes de verdade, estratégias de poder e formas de subjetividade que são específicas (FOUCAULT, 2006).

Para Michel Foucault (2001), a figura do leproso é substituída pela do louco, no final da Idade Média. Na Renascença, a loucura era uma representação da inquietude da sociedade sobre os limites da própria razão, e, assim, era vista como a fronteira entre o permitido e o proibido, entre o mundano e o sagrado. Apenas no começo da modernidade, o grande processo de internação massiva das populações desajustadas permitiu, no interior da internação inespecífica, a objetivação do louco ${ }^{4}$. Pela primeira vez na história, o grande encarceramento passa a produzir esta figura ambivalente do louco, neste momento, o louco é separado da imagem da loucura. O asilo, no século XVIII, isola o louco dos demais desclassificados da sociedade. O nascimento do asilo na idade clássica, juntamente com a invenção da psiquiatria, produz o louco agora como doente mental a ser submetido a estratégias de poder e formas de conhecimento específico da condição de

\footnotetext{
3 O termo medicalização surgiu no interior das obras de Michel Foucault (2006), a partir de leituras realizadas por Machado (1978). Iniciou-se como poder médico e aos poucos o termo ganhou autonomia explicativa para compreender o processo mais amplo de psiquiatrização da sociedade por meio do uso disseminado de medicamentos psiquiátricos. Uma discussão mais profunda sobre as consequências da medicalização da vida pode ser encontrada em Rose (2013), tendo como parâmetro a discussão sobre biopolítica de Foucault.

4 Este processo se dá com a criação do Hospital Geral em 1656, local para pobres, desempregados, correcionários e insanos. "O internamento dos alienados é a estrutura mais visível da experiência clássica da loucura. (...) Hospital Geral não é estabelecimento médico é uma estrutura semi jurídica: decide, julga e executa: soberania quase absoluta, jurisdição sem apelações, direito de execução contra o qual nada pode prevalecer: estranho poder que o rei estabelece entre a polícia e a justiça, nos limites da lei" (FOUCAUT, 2001: p. 50).
} 
internação asilar. De forma mais específica, o asilo é criado como instrumento de análise, investigação e como condição necessária para a construção do saber médico-psiquiátrico. Ao internar o louco, produz-se uma objetividade que cinde o mundo dos normais daquele dos anormais, um campo de observação e controle do saudável em relação ao doente mental. No interior do asilo, os mecanismos de cura e de tratamento dispostos pela psiquiatria nascente são na verdade formas de um saber-poder disciplinar que separa e legitima o poder do médico sobre os asilados; a doença mental emerge como este lócus de um espaço disciplinar. A vontade insurgente do louco é submetida à vontade tirânica médica em sua busca pela submissão do louco às terapias emergentes então propostas que mais tinham relação com controle do que com tratamento propriamente dito (FOUCAULT, 2001; 2006).

O asilo é convertido em hospício no século XIX quando a psiquiatria nascente se torna saber hegemônico relativo à loucura; o hospital psiquiátrico é invenção do saber médico que é exercido no espaço asilar, com objetivo declarado não de conter a loucura delirante, mas como lugar de diagnóstico, tratamento, observação e cura da loucura: é a chamada idade de ouro do alienismo ${ }^{5}$, que inscreve o louco no interior da alienação mental. Junto à prática do internamento, a loucura deixa de ser compreendida como uma perturbação do juízo, como oposta à razão, como a resultante perda de capacidade de julgamento moral; a loucura agora de forma mais objetivada possível torna-se um distúrbio psíquico que prejudica, no louco, sua capacidade de agir e querer: a loucura, neste momento, é vista como insurreição, como uma vontade não dominada, não submetida aos ditames da razão. Até o século XVIII, a loucura era considerada a partir da perspectiva do erro. O louco, no século XIX, é caracterizado como aquele que não se submete ao poder; o asilo tem o papel de subjugar a vontade do louco à razão psiquiátrica, o asilo passa a se tornar uma máquina de classificação da normalidade (FOUCAULT,

\footnotetext{
${ }^{5} \mathrm{O}$ alienismo surgiu na virada do século XVIII para o século XIX como um saber que propunha uma solução médica e científica à loucura. Nele, a loucura passou ser vista não mais como erro, mas como uma doença mental cujas causas podiam ser identificadas em termos de causas físicas ou morais. É criado, neste contexto, o conceito de alienação mental e moral, que vai dar ocasião para um amplo processo de captura da loucura. No Brasil, a inauguração do Hospício Pedro II, em 1852, é tido como marco do alienismo no país. (RAMOS; TEIXEIRA, 2012). A crítica ao alienismo surge na mesma época e é recebida até mesmo na literatura no famosos O Alienista de Machado de Assis e, mais tardiamente, no Cemitério dos Vivos de Lima Barreto.
} 
Revista NEP, Núcleo de Estudos Paranaenses, Curitiba, v.4, n.2, dez. 2018

2006). No momento de especificação da loucura como doença mental, não apenas um campo novo de saber e novas práticas de poder emergem, como também o signo da loucura passa a ser estendido para o corpo social inteiro. $\mathrm{O}$ alienismo, ao ampliar o quadro nosográfico da loucura, passa a identificar os desvios da normalidade e a assumir um papel preventivo e profilático de higiene do corpo social. Portanto, a história dos hospitais psiquiátricos é analisada, na obra de Foucault, como a história da constituição de mecanismos de especificação, controle, segregação e cura dos loucos (FOUCAULT, $2001)^{6}$.

\section{Breve histórico da psiquiatria no Brasil}

No Brasil, a psiquiatria conhecerá uma primeira versão na forma do alienismo. $\mathrm{O}$ saber médico sobre a loucura é desenvolvido no país, sobretudo a partir da presença conspícua de alienistas na internação asilar, não apenas fazendo diagnósticos e propondo terapias, mas também construindo asilos e cuidando de sua gestão: é a fase dos grandes hospícios. Começando com o Hospício Nacional dos Alienados do Rio de Janeiro e depois com o Hospício dos Alienados do Juquery, a psiquiatria no Brasil foi tida como uma grande promessa de cura e tratamento da loucura ${ }^{7}$. Uma considerável quantia de recursos públicos e a institucionalização da medicina psiquiátrica nas faculdades de

\footnotetext{
6 “O que tudo isso nos ensina senão que a psiquiatria é uma terapêutica sem medicina, que os procedimentos utilizados como curativos são efetivamente técnicas de controle, relações de força unilaterais que se formulam em termos de autoridade e de domínio? A ação do psiquiatra é moral e social, e não depende necessariamente, para sua eficácia, de competência científica: desalienar é instaurar uma ordem moral. A medicina mental é uma terapêutica, uma educação moral, característica que, até nossos dias, ainda a acompanha. O que, de um ponto de vista teórico ou conceitual, só é possível porque o louco não é mais, como na época clássica, um desarrazoado, isto é, o outro do pensamento e da mora, mas um alienado, o que teoricamente permite a recuperação, a transformação ou a cura na medida em que, sob a alienação, existe no mais do íntimo do homem algo inalienável que é explicitado pela psiquiatria em termos de natureza, verdade, razão, moral social, etc. Se a loucura é alienação, sua cura é retorno ao inalienável pela ação exercida pelo hospício. Chegou para o louco, e cada vez mais para todos nós, a era do patológico" (MACHADO, 2006: p. 81).

${ }^{7}$ Durante o Segundo Império, os insanos eram internados na Santa Casa de Misericórdia; em 1852 foi criado o Hospício Pedro II, com capacidade para 300 internos; em 1889, passa a se chamar de Hospício Nacional de Alienados e, sob a direção de Juliano Moreira, promete um tratamento médico adequado aos internos visando a sua cura; em São Paulo, vai caber a Franco da Rocha a criação do Juquery, num local distante da capital, onde futuramente será construído um complexo asilar constituído por colônias de trabalho, Manicômio e Assistência Social, local que será o núcleo original da cidade de mesmo nome (CUNHA, 1988; ENGEL, 2001).
} 
Revista NEP, Núcleo de Estudos Paranaenses, Curitiba, v.4, n.2, dez. 2018

medicina deram um razoável poder ao médico psiquiatra dentro e fora dos asilos. Os grandes asilos, com o passar dos anos, não cumpriram seu papel de conhecimento e cura da doença mental e, aos poucos, foram perdendo relevância e se converteram em grandes depósitos de loucos, nas condições mais abjetas. Além da intervenção clínica e asilar, a psiquiatria no país, sobretudo no início do século $\mathrm{XX}$, adquire técnicas preventivas de controle social introduzindo novas práticas institucionais, ambulatoriais e clínicas. Esse processo possibilitou a descentralização dos grandes hospícios, antes apenas localizados nas capitais, para as regiões interioranas, atendendo a demanda das recentes faculdades de medicina. Neste período, surgem políticas de saúde mental, como concretização dos projetos psiquiátricos, com fortes conotações racistas, sexistas e eugênicas. (FONTES, 2011; CUNHA, 1986; COSTA, 1980 e 1999).

Ao longo da década de 1930, a rede ambulatorial e de atendimento clínico passa a ser regulamentada pelo governo federal. Como consequência o Estado passa a concentrar a definição das políticas de saúde mental, do controle e da fiscalização das práticas psiquiátricas. Na década de 1940, são iniciadas ações políticas de caráter assistencial na área da saúde mental, acompanhando a reforma das políticas de saúde. Em 1941, é criado o Serviço Nacional de Doenças Mentais (SNDM) que autoriza a realização de convênios com os governos estaduais para a criação de hospitais psiquiátricos. A partir de 1960, a rede de hospitais psiquiátricos é expandida no país e há um remanejamento de recursos públicos para hospitais privados e conveniados, possibilitando a criação de mais leitos para internações; a internação, assim, passa a refletir esta articulação entre público e privado e, em razão disto, se torna lucrativa para as entidades de assistência social. Esse modelo dúplice tinha outra característica importante que vai permanecer até os dias de hoje: a internação dependia tanto da vontade dos familiares como da intervenção médica, num dispositivo ampliado de captura daquele considerado louco (FONTES, 2011).

Por volta de 1970, a situação dos hospitais psiquiátricos torna-se insustentável: maus-tratos, ausência de assistência psicossocial, isolamento das famílias, degradação das condições de permanência. Mas estas condições assinalam de forma mais profunda uma crise do sistema do grande internamento asilar no país. Em decorrência disto, entidades e movimentos sociais, como o Movimento de Trabalhadores da Saúde Mental (MTSM), passam a criticar o modelo asilar dando início ao Movimento Antimanicomial que passa a dirigir críticas à instituição psiquiátrica, especialmente ao modelo centrado no hospital, Dossiê Direitos Humanos, Violência e Criminalidade

ISSN: 2447-5548 
acentuando a necessidade de reforma do aparelho psiquiátrico no país (AMARANTE, 1996; LOUGON, 2006). O movimento, tardiamente, passa a reproduzir todo um debate e uma nova concepção sobre o papel do tratamento ambulatorial e a inserção do louco na comunidade, o que estava acontecendo na Europa desde os anos 1960 no interior da antipsiquiatria $^{8}$. Assim, a crítica e a luta contra as práticas psiquiátricas centradas em instituições asilares possibilitaram a experiência de meios de tratamento substitutos, concentrados em uma modalidade ambulatorial e assistencial, nesta perspectiva, em meados de 1980, são criados os primeiros Centros de Atenção Psicossocial (CAPS) e os Núcleos de Atenção Psicossocial (NAPS). O $1^{\circ}$ Congresso Nacional de Saúde Mental coloca em pauta um projeto de lei pela regulamentação dos direitos das pessoas portadoras de transtornos mentais (PPTM), com a previsão de extinção dos asilos progressivamente no país. Os modelos de atendimento CAPS, NAPS e Hospital-Dia são regulamentados e se consolidam como plano de governo pelas portarias 189, de 1991, e 224, de 1992. Também são aprovadas normas de fiscalização e classificação dos hospitais psiquiátricos, dando principalmente ênfase aos serviços extra-hospitalares. Estes têm como objetivo "substituir uma psiquiatria centrada no hospital por uma psiquiatria sustentada em dispositivos diversificados, abertos e de natureza comunitária ou territorial, esta é a tarefa da reforma psiquiátrica" (TENÓRIO, 2002, p.35). No entanto, a prática de internação não é excluída, pois a portaria 224, de 1992, do Ministério da Saúde, dividiu a internação em hospitalar e ambulatorial. A primeira foi subdividida em internação e semi-internação, permitindo a intervenção psiquiátrica na forma da internação voluntária, involuntária e compulsória (Lei 10.216, 2001).

\section{Política de saúde mental no Brasil contemporâneo}

Com as mudanças nas políticas de saúde mental, após a constatação da degradação das instituições asilares, a internação deixou de ser central e passou a ser parte de um rol de práticas de intervenção. A despeito disto, a internação continuou como peça

\footnotetext{
${ }^{8}$ As discussões de Michel Foucault, o trabalho de Franco Basaglia e a obra de Roberto Machado foram essenciais para a discussão sobre a crise do grande asilo, para a discussão sobre luta antimanicomial e sobre a noção de poder médico (MACHADO, 1978; BASAGLIA, 2001; FOUCAULT, 2006).
} 
indispensável nas estratégias psiquiátricas. Segundo a Lei 10.216 de 06 de abril de 2001, marco da reforma psiquiátrica no país, em que se procura assegurar os direitos das pessoas portadoras de transtornos mentais (PPTM), a internação deve ser acionada quando se esgotam os recursos extra-hospitalares, como atendimento ambulatorial e uso de medicamentos, por exemplo. Entretanto, várias situações têm provocado o uso sistemático da internação: usuários de crack; intervenções na chamada Cracolândia e a figura da internação compulsória; o chamado surto psiquiátrico ${ }^{9}$ e outros episódios de suposto descontrole de diagnosticados como PPTM. Estes episódios permitem mobilizar a intervenção psiquiátrica na forma da internação, seja em hospitais gerais, hospitais psiquiátricos ou manicômios judiciários ${ }^{10}$.

Atualmente, a Rede de Atenção Psicossocial (RAPS), instituída em 2011 e tida como expressão da reforma psiquiátrica no país, articula diretrizes para o funcionamento do aparelho de atenção à saúde mental. Segundo o documento de responsabilidade do Ministério da Saúde, "Saúde Mental em Dados - 12" de 2015, o CAPS alcançou 2.209 unidades em 2014, o número dobrou desde 2006. Aliado a isso, nota-se o aumento de financiamento ao sistema, especialmente ao CAPS III e CAPSad (álcool e drogas),

\footnotetext{
${ }^{9} \mathrm{O}$ termo surto aparece em alguns manuais que orientam a prática médica psiquiátrica de forma pouco definida indicando a dimensão fenomênica e temporal de algum tipo de descontrole psíquico e comportamental. No Manual Diagnóstico e Estatístico de Transtorno Mentais (DSM-5), 2014, o surto aparece associado aos termos: psicótico, episódico, abrupto e desenfreado, como, por exemplo, "surto desenfreado de compras" (p.124) ou "surto abrupto de medo" (p.208), sendo uma característica ou critério diagnóstico. Segundo Dalgalarrondo (2008): “ O surto, segundo a noção da patologia geral (mas assumida pela psicopatologia), é uma ocorrência aguda que se instala de forma repentina, fazendo eclodir uma doença de base endógena, não compreensível psicopatológicamente"(p.297); o autor inclui o surto como um conceito dentre as evoluções temporais dos transtornos mentais e como uma classificação dos fenômenos agudos ou subagudos, se caracterizando por produzir "sequelas irreversíveis, danos à personalidade e/ou à esfera cognitiva do indivíduo." e pelo qual o indivíduo "sai diferente" depois de ser acometido. Termo, portanto, muito vago e amplo que permite o acionamento de diferentes dispositivos de poder, não apenas o dispositivo psiquiátrico (Foucault, 2006).

${ }^{10}$ Manicômios judiciários são instituições asilares criadas para acolher pessoas que cometeram crimes mas foram consideradas inimputáveis pela justiça em razão de doença mental. A história dos manicômios é longa e problemática. São instituições que ainda existem e têm inúmeros problemas pois são instituições ambivalentes pertencentes à justiça e à saúde; sendo assim, são espaços de isolamento permanente que se assemelham a campos de concentração. Mais recentemente, na política de segurança pública, pessoas que cometeram crimes considerados gravíssimos são internadas em Hospitais de Custódia e Tratamento Psiquiátrico, vinculados à Secretaria da Administração Penitenciária em geral em situação jurídica questionável. O Estado de São Paulo tem três HCTP e alas psiquiátricas nos presídios, lócus de várias violações de direitos humanos.
} 
sobretudo a partir de 2013 em razão da maior visibilidade do "problema do crack"11. Em 2014, as unidades hospitalares com número de leitos especializados em saúde mental contavam com 888 leitos, sendo estes distintos dos leitos especializados em psiquiatria. No ano de 2014, conforme o registro do PNASH (Programa Nacional de Avaliação dos Serviços Hospitalares) e CNES (Cadastro Nacional de Estabelecimentos de Saúde), havia 4.620 leitos destinados ao SUS em hospitais gerais para estes casos. Neste mesmo ano, os leitos em hospitais psiquiátricos somavam 25.988. Segundo relatório do PNASH, em 2016, são 104 hospitais psiquiátricos no Brasil. Não obstante a rede de atendimento ter crescido, ao menos 27 unidades hospitalares foram consideradas impróprias em razão de maus-tratos, falta de higiene, falta de médicos etc. (BRASIL, 2015).

Em 14 de dezembro de 2017, o Ministério Público, a Associação Brasileira de Psiquiatria e a Federação Nacional das Comunidades Terapêuticas, em uma reunião da Comissão Intergestores Tripartite (CIT), aprovaram a Resolução $\mathrm{n}^{\circ} 32$ que dá centralidade novamente aos hospitais psiquiátricos e às comunidades terapêuticas no tratamento de PPTM. A medida procura garantir a permanência de leitos em hospitais psiquiátricos por meio do reajuste do valor da diária paga por internação em hospitais psiquiátricos, assim como aumento de leitos psiquiátricos em hospitais gerais e aumento do credenciamento e de financiamento de comunidades terapêuticas (BRASIL, 2017; ABRASME, 2018).

Mesmo que as políticas públicas atuais da área da saúde mental proponham a desinternação e o tratamento ambulatorial para a maioria dos casos diagnosticados, os limites da definição do que é uma doença mental e as estratégias de controle social baseadas na noção de risco permitem acionar, dentro da lei, os mecanismos de intervenção psiquiátrica. Nestes casos, o episódio do surto e o diagnóstico da "dependência" de crack têm sido instrumentos poderosos para justificar a retomada das internações psiquiátricas

\footnotetext{
$11 \mathrm{O}$ crack e as cracolândias tiveram impacto nas políticas públicas que ganharam aporte financeiro e técnico importante nos últimos anos; na prática, a Rede de Atenção Psicossocial compreende a atenção básica ambulatorial 24 horas, mas dedica espaço e recursos para programas de internação, incluindo mais leitos e, dentre eles, as chamadas Comunidades Terapêuticas. Sendo assim, as políticas de saúde mental são ambivalentes, pois públicas e privadas e laicas e religiosas. Mais complicado mesmo é que a margem entre PPTM, usuários de álcool e de drogas se tornou menor com estas iniciativas, acabando por se indiferenciar. Disponível em: <http://www.brasil.gov.br/observatoriocrack/index.html/cuidado/outros-centros-atencaopsicossocial.html . Acesso em: 10/05/2018.
} 
no mundo contemporâneo. A noção de risco, modo de operação característico da modernidade, baseia-se na avaliação de possibilidades de prejuízos no futuro e, por isto, permite ativar formas preventivas de controle, como o modelo ambulatorial de atuação do aparelho psiquiátrico (ENGEL, 2001; GIDDENS, 1999; BECK, 2010).

Por exemplo, em maio de 2017, a prefeitura da cidade de São Paulo propôs a medida legal de proteção e direitos do portador de transtorno mental, que na verdade, flexibilizou as proteções previstas na Lei 10.216, de 2001, a chamada lei da reforma psiquiátrica e da proteção das PPTM. A medida, na prática, autoriza o uso da internação compulsória para o internamento usuários de drogas na região da "Cracolândia" $"$. Esta flexibilização ocorre no momento em que há uma maior aceitação por parte da mídia das medidas de internação (AZEVEDO \& SOUZA, 2017).

A generalização dos termos "dependência"; "usuário de drogas"; "uso abusivo de drogas"; "dependente de crack" tem possibilitado a aceitação da privação de liberdade como medida obrigatória. Trata-se, portanto, de uma generalização do risco, do uso de medidas de exceção, de controle biopolítico da população urbana. Se a lei deve ser pautada pela análise de casos específicos para a partir daí realizar o diagnóstico e propor as formas mais adequadas e menos danosas de intervenção, as decisões da cidade de São Paulo ampliam perigosamente a margem de liminaridade da ação do poder psiquiátrico, policial e judicial. A ativação da internação compulsória se coloca, nestes casos, como política governamental de controle social e sendo assim é muito problemática (GUARESCHI ET ALL, 2016; AZEVEDO \& SOUZA, 2017) ${ }^{13}$.

\footnotetext{
${ }^{12}$ No dia 26 e maio de 2017, o Juiz da $7^{\text {a }}$ Vara da Fazenda Pública da Capital concedeu liminar à Prefeitura de São Paulo autorizando a busca e apreensão para avaliação e internação compulsória de pessoas usuárias de drogas, baseando-se na lei 10.216, de 2001, que autoriza a internação compulsória no que se refere a transtornos mentais. A justiça extinguiu a ação, após fortes críticas da comunidade e de especialistas da área da saúde. No Rio de Janeiro a medida foi autorizada em 2011, para crianças e adolescentes (BRASIL, 2011). Apesar das constantes críticas à medidas como esta, o fato é que a internação compulsória está sendo adotada cotidianamente e direcionando PPTM para o sistema de saúde mental que vê a demanda aumentar enormemente, sobretudo para comunidades terapêuticas, clínicas particulares e hospitais espíritas.

13 Esta generalização de um estado de exceção para as PPTM e para os usuários de crack tem uma implicação mais ampla na disseminação da medicalização das doenças e síndromes psiquiátricas, mas também da medicalização geral da sociedade. A contraface perversa desta tendência aparece claramente na campanha lançada pela Associação Brasileira de Psiquiatria (ABP) contra o que os médicos psiquiatras estão chamando de psicofobia: preconceito contra as pessoas portadoras de transtornos mentais que mobiliza estratégias de perseguição e incompreensão às diferenças e às multiplicidades.
} 
Revista NEP, Núcleo de Estudos Paranaenses, Curitiba, v.4, n.2, dez. 2018

\section{O surto como categoria de governo da loucura}

Para o presente texto, vale a pena ressaltar o problema do surto psiquiátrico como parte do dispositivo mais amplo de reativação da internação psiquiátrica no Brasil contemporâneo. Estudos sobre o surto são inexistentes nas Ciências Sociais. Na área da psiquiatria, em geral, o surto é abordado em manuais para fins de diagnóstico e de intervenção. Pouco se fala, portanto, sobre o surto em termos de pesquisa científica, embora a noção de surto tenha se tornado lugar comum na linguagem cotidiana. Destacam-se duas formas de acionamento da internação: quando o "surto" é identificado pela família ou pelo médico; o mesmo processo ocorre nos casos de solicitação de internação de usuários de drogas. Tentando refletir um pouco sobre isso, a internação pode ser tomada como medida de exceção. No momento em que ela é solicitada pela família ou pelos profissionais, ela rompe com as garantias constitucionais da pessoa que é submetida a um poder sobre o qual não possui o direito de se pronunciar ou resistir. A medida da internação, assim, ganha força de lei; a consequência disto é que ela introduz no espaço da lei um princípio de normalização; ela introduz na norma jurídica o espaço de necessidade. Em outros termos, o surto cria a necessidade da medida de internação, naturaliza o risco e a intervenção, criando um espaço vazio na lei e construindo um verdadeiro estado de exceção (AGAMBEN, 2004). A internação deixa de ser apenas e tão-somente um mecanismo psiquiátrico de último recurso e passa a ser utilizada como ferramenta de captura dos corpos que se apresentam como risco social. A internação, por outras vias, passa a ocupar um lugar central nas estratégias de controle social. (COELHO; OLIVEIRA, 2014).

$\mathrm{Na}$ obra de Michel Foucault o poder psiquiátrico foi constituído a partir da inquietação provocada pela loucura e, aos poucos, o modelo da internação asilar foi sendo usado para sequestrar o corpo do louco para fins de estudos, controle, prevenção e tratamento (Foucault, 2006). Hoje a noção de surto parece ocupar um lugar destacado nas estratégias de internação e medicalização da sociedade. Não mais a internação do louco, mas todo um dispositivo acionador da internação a partir de episódios no comportamento das pessoas que não têm estatuto de doença para a psiquiatria. A confusão entre doença mental, síndrome, transtornos, surtos e uso de substâncias psicoativas é parte integrante deste dispositivo de captura que tende a se converter numa estratégia geral de gestão de Dossiê Direitos Humanos, Violência e Criminalidade

ISSN: 2447-5548 
riscos. A gestão dos corpos revoltados ou transgressores encontra no surto, na internação e na medicalização sua forma excelente e sua justificativa mais persuasiva ${ }^{14}$. Tanto é verdade que a noção de surto passa a ser de domínio comum e a prática do autodiagnostico torna-se mais usada pelas pessoas. O poder psiquiátrico, neste momento, não apenas reflete uma dimensão ampliada do poder médico, mas também dá a outros poderes a capacidade de gerir problemas sociais e neste sentido surto é uma instância de descontrole social: medidas de saúde mental, medidas urbanas, medidas jurídicas, medidas de segurança são justificáveis, agora, fora do espaço da lei, para restabelecimento da norma e para gestão dos riscos de revolta. Assim, acreditamos que o surto se configura como uma tradução individual e psíquica do estado de exceção, estendendo seus efeitos de desativação das proteções legais e jurídicas. O surto pode ser compreendido como uma peça essencial da moderna psiquiatria que tem por um lado a internação como estratégia local e o medicamento como tática geral. O surto ativa a internação que opera como uma exceção à norma psiquiatra, que preconiza a não internação, para fazer funcionar de forma geral esta mesma norma. (AGAMBEN, 2004) ${ }^{15}$.

Foucault $(2001 ; 2006 ; 2008)$ dá indicações da passagem da psiquiatria centrada em um modelo disciplinar de poder que se exerce sobre o corpo individual para um modelo biopolítico, de governamentalização do corpo social mais amplo. O processo de diagnóstico e de tratamento da loucura pela psiquiatria colocou, ao longo do século XIX, sua ênfase em mecanismos de poder-saber como o interrogatório e as drogas. O interrogatório é o dispositivo privilegiado da psiquiatria na composição do diagnóstico. Ele tem uma dupla função: servir de mecanismo disciplinar fazendo com que o indivíduo confesse a sua loucura e inscrever o episódio de loucura na possibilidade da doença, por

\footnotetext{
14 Para uma revisão do debate sobre medicalização e seus efeitos na sociedade contemporânea ver Soares (2018). De fato, nas duas últimas décadas o CID-10 cresceu de forma significativa sobretudo ao incluir a categoria das síndromes como objeto de intervenção médica. Disponivel em: 〈http://www.cid10.com.br/>. Acesso em: 20/04/2018. O DSM-5, por sua vez trabalha com a noção de transtorno mental, cuja definição é também muito vaga. Considerando o quadro da inespecificação da doença mental, da ampliação da noção de doença por meio das síndromes e por meio dos usuários de substâncias psicoativas, assim como a universalização do medicamento auto ou hetero administrado, o quadro do poder sobre a vida exercido pela psiquiatria se expandiu de forma dramática.
}

15 O Estado de exceção, segundo Agamben (2004), é convertido em norma, é o mecanismo através do qual o estado exerce seu poder normativo. A norma se aplica na exceção, que é acionada sempre que necessário, neste sentido, a lei precisa do estado de exceção para ser ativada. A categoria surto, como dispositivo de captura da psiquiatria introduz uma anomia no corpo social para tornar possível a normatização efetiva. 
meio da identificação do poder psiquiátrico nos antecedentes familiares, hábitos e conduta do interrogado de traços de anormalidade.

As políticas de saúde mental contemporâneas são constituídas por diferentes instituições e práticas. O manicômio judiciário, por exemplo, se articula ao modelo do poder soberano na forma de autorizações judiciais; ao modelo disciplinar, quer por meio de instituições públicas ou religiosas; e ao modelo da biopolítica na forma da gestão da população. Em outros termos, o poder psiquiátrico funciona em rede e esta é acionada pela doença, pelo surto e pelos potenciais riscos dos indivíduos diagnosticados com transtornos mentais.

\section{Conclusões}

As relações de poder perpassam as instituições e constituem indivíduos, pela inscrição da loucura no corpo da população como perigo e risco, por mecanismos de poder-saber: práticas que produzem discursos e modos de sujeição. A loucura como perigo social, possibilitou a psiquiatria no século XIX sua especialização como aparato da higiene pública e a medicalização do social objetivando não mais curar, mas manter a ordem social. Com isto, a biopolítica se estabelece como governamentalidade do corpo social. As estratégias de controle social da psiquiatria contemporânea baseadas no episódio do surto e na generalização do termo "dependência de drogas", alinham tanto a biopolítica na forma de mecanismos preventivos que visam a reinserção do "anormal" no meio social, especialmente pelo uso massivo de medicamentos, como o poder soberano e disciplinar, através de medidas que se configuram como estados de exceção no âmbito individual e que permitem a intercepção, a captura e a internação daqueles que não se enquadram na régua da normalidade.

Nesta perspectiva que alia a noção de estado de exceção e de gestão biopolítica, o surto ativa o poder psiquiátrico, o poder policial e o poder judiciário. Desta forma, a loucura, em sua relação paradoxal com outras afecções consideradas mentais como o uso de drogas, se torna um problema de segurança. A generalização do dispositivo psiquiátrico permite a gestão do corpo vivo da população, em termos de uma ampliada medicina do corpo social, mobilizando a noção de surto, de dependência de drogas, normal e anormal, em um aparelho hibrido que proporciona o diagnóstico, o atendimento 
Revista NEP, Núcleo de Estudos Paranaenses, Curitiba, v.4, n.2, dez. 2018

ambulatorial, o uso de medicamentos e a internação, para imobilização daquelas pessoas que manifestam seu inconformismo social.

\section{Referências}

ABRASME. Crônicas da resistência: Em tempos de desconfiguração da Política Nacional de Saúde Mental, Álcool e outras Drogas. Boletim de Saúde Mental 01. São Paulo: Abrasme, 2018.

AGAMBEN, Giorgio. Estado de exceção. São Paulo: Boitempo, 2004.

AMARANTE, Paulo Duarte de Carvalho. O Homem e a serpente: outras histórias para a loucura e a psiquiatria. Rio de Janeiro: Editora Fiocruz, 1996.

AMERICAN PSYCHIATRIC ASSOCIATION. DSM-5 - Manual Diagnóstico e Estatístico de Transtornos Mentais. Porto Alegre: Artmed, 2014.

AZEVEDO, Américo Orlando \& Tadeu de Paula Souza. Internação compulsória de pessoas em uso de drogas e a contrarreforma psiquiátrica brasileira. Physis. Revista de Saúde Coletiva, Rio de Janeiro, 27 [ 3 ]: 491-510, 2017.

BASAGLIA, Franco. A Instituição negada: relato de um hospital psiquiátrico. Rio de Janeiro: Graal, 2001.

BECK, Ulrich. Sociedade de risco: rumo a uma outra modernidade. São Paulo: Editora 34, 2010.

BRASIL. Resolução n 32 de 14 de dezembro de 2018. Brasília - DF, 2017.

BRASIL. Lei 10.216, de 06 de abril de 2001. Brasília- DF, 2001.

BRASIL. Secretaria Municipal de Assistência Social. Resolução n²0 de 27 de maio de 2011. Brasília - DF, 2011.

BRASIL. Saúde Mental em Dados 12. Ministério da Saúde Secretaria de Atenção à Saúde Departamento de Ações Programáticas Estratégicas Coordenação Geral de Saúde Mental, Álcool e Outras Drogas. Ano 10, nº 12, outubro de 2015. Brasília - DF, 2015.

BRASIL. Portaria/SNAS nº 189 - De 19 de novembro de 1991. Brasília-DF, 1991.

BRASIL. Portaria $n^{\circ}$ 224/ms, de 29 de janeiro de 1992. Brasília-DF, 1992.

BRASIL. Ministério da Saúde. Secretaria de Atenção à Saúde. DAPE. Coordenação Geral de Saúde Mental. Reforma psiquiátrica e política de saúde mental no Brasil. 
Documento apresentado à Conferência Regional de Reforma dos Serviços de Saúde Mental: 15 anos depois de Caracas. OPAS. Brasília, novembro de 2005.

CARRARA, Sérgio. Crime e Loucura: O aparecimento do manicômio judiciário na passagem do século. Rio de Janeiro: EdUERJ; São Paulo: EdUSP, 1998.

COELHO, Isabel; OLIVEIRA, Maria Helena Barros de. Internação compulsória e crack: um desserviço à saúde pública. SAÚDE DEBATE | Rio de Janeiro, v. 38, n. 101, P. 359-367, abr./jun 2014. Disponível em: <http://www.scielo.br/pdf/sdeb/v38n101/0103-1104-sdeb-38-101-0359.pdf>. Acesso em: 25/09/2017.

COSTA, Jurandir Freire. A história da psiquiatria no Brasil. Rio de Janeiro: Campus, 1980.

COSTA, Jurandir Freire. Ordem médica e norma familiar. Rio de Janeiro: Graal, 1999.

CUNHA, Maria Clementina Pereira da. Espelho do mundo. Juquery: A história de um asilo. Editora Paz e Terra, $2^{\circ} \mathrm{Ed}, 1988$.

DALGALARRONDO, Paulo. Psicopatologia e semiologia dos transtornos mentais 2. ed. Porto: Artmed, 2008.

ENGEL, Magali Gouveia. Os Delírios da Razão: Médicos loucos e hospícios. Editora: Fiocruz, Rio de Janeiro, 2001.

FONTE, E. M. M. Da institucionalização da loucura à reforma psiquiátrica: as sete vidas da agenda pública em saúde mental no brasil. Estudos de Sociologia, 2011, p. 112. 17

FOUCAULT, Michel. História da Loucura na idade clássica. Tradução: José Teixeira Coelho Neto. $8^{\text {a }}$ edição. São Paulo: Perspectiva, 2001.

O Poder Psiquiátrico: curso no Collège de France (1973-1974). São Paulo: Martins Fontes, 2006.

Ditos e Escritos I. Problematização do sujeito: psicologia, psiquiatria e psicanálise. Rio de Janeiro: Forense Universitária, 2006a.

Os anormais: curso no Collège de France (1974-1975). São Paulo: Martins Fontes, 2001a.

Segurança, Território, População. São Paulo: Martins Fontes, 2008.

GIDDENS, Anthony. Mundo em descontrole. O que a globalização está fazendo de nós. Rio de Janeiro: Record, 2000. 
GUARESCHI, Neuza Maria de Fátima; Lutiane de Lara; Daniel Dall'Igna Ecker. A internação compulsória como estratégia de governamentalização de adolescentes usuários de drogas. Estud. psicol. Natal, v.21, n.1, jan./mar. 2016.

LOUGON, Mauricio. Psiquiatria Institucional: do hospício à reforma psiquiátrica. Rio de Janeiro: Editora Fiocruz, 2006.

MACHADO, Roberto (org) Danação da norma: medicina social e constituição da psiquiatria no Brasil. Rio de Janeiro: Graal, 1978.

Foucault, a ciência e o saber. Rio de Janeiro: Jorge Zahar Editor, 2006.

ROSE, Nikolas. A política da própria vida: biomedicina, poder e subjetividade no século XXI. São Paulo, Paulus, 2013.

RAMOS, Fernando A. de Cunha; TEIXEIRA, Manoel Olavo Moureiro. As origens do alienismo no Brasil: dois artigos pioneiros sobre o Hospício de Pedro II. Rev. Latinoam. Psicopat. Fund., São Paulo, v. 15, n. 2, p. 364-381, junho 2012. Disponível em: <http://www.scielo.br/pdf/rlpf/v15n2/11.pdf >. Acesso em: 30/08/2017.

SOARES, Sílvio de Azevedo. Medicalização do social e dispositivo psiquiátrico nos Ditos e Escritos genealógicos de Foucault: instrumento disciplinar e estratégia biopolítica. Comunicação apresentada no GT2: Sociologia da Saúde. IX Seminário Nacional Sociologia \& Política. Maio, 2018, Curitiba.

TENÓRIO, Fernando. A reforma psiquiátrica brasileira, da década de 1980 aos dias atuais: história e conceito. História, Ciências, Saúde Manguinhos, Rio de Janeiro, vol. 9(1): 25-59, jan.-abr. 2002. Disponível em: <http://www.scielo.br/pdf/hcsm/v9n1/a03v9n1.pdf >. Acesso em: 19/08/2017.

Recebido: 10 set. 2018

Aceito: 16 nov. 2018 